\title{
SOCIAL VARIABLES AS DETERMINANTS OF SUICIDE BEHAVIOUR AMONG ADOLESCENTS IN RIVERS STATE, NIGERIA
}

\author{
Essien, B.S. \\ Department of Educational Psychology, Guidance and Counselling, \\ Faculty of Education, University of Port Harcourt \\ Prof. Awujo, C.G. \\ Department of Educational Psychology, Guidance and Counselling, \\ Faculty of Education, University of Port Harcourt
}

Citation: Essien, B.S., and Awujo, C.G. (2022) Social Variables as Determinants of Suicide Behaviour among Adolescents in Rivers State, Nigeria, British Journal of Education, Vol.10, Issue 2, pp. 1-12

\begin{abstract}
This study investigated some social variables as determinants of suicide behaviours among adolescents in Rivers State, Nigeria. It adopted the correlational research design. The population of the study was 785 students of the three federal Government Colleges in Rivers State who manifest suicide behaviour. Using purposive sampling, they were drawn to ensure that only those that elicited suicide behaviours were used for the study. Three research questions and three hypotheses were tested in the study at 0.005 level of significant. Two instrument named suicide behaviour questionnaire- revised (SBQ-R) and determinants of suicide behaviour questionnaire (DSBQ) were used for the study. The $S B Q-R$ was adapted and used to find out those that exhibit suicide behaviour while DSBQ was used to gather information on the independent variables such as substance abuse and sexual abuse. Experts in measurement and evaluation validated the instruments. The reliability index was 0.85 for $S B Q-R, 0.81$ for substance abuse and 0.68 for sexual abuse using Cronbach via SPSS. Simple regression was used to answer research questions 1 and 2 and its corresponding hypotheses while multiple regression was used to answer research questions 3 and its corresponding hypothesis at 0.005 alpha level. Findings were that substance abuse $(p=0.000<0.005)$, sexual abuse $(0.000<0.005)$ and joint social variables $(p=0.00<0.05) \quad$ relates significantly with suicide behaviour. Based on the findings it was recommended that substances that are easily abused by adolescents should be kept out of their reach and Government parastatals like the Nigerian Drug and Law Enforcement Agency (NDLEA) and CUSTOM officials that are in charge of ensuring that these dangerous substances do not see the light of the day should intensify their efforts in seizing and destroying them. Those that are traffickers of these substances should be counselled with therapies like CBT to help them stop trafficking dangerous substances. Perpetrators of sexual abuse should also be re-orientated, counselled and rehabilitated.
\end{abstract}

KEYWORDS: suicide, suicide behaviour, adolescents, substance abuse and sexual abuse 


\section{INTRODUCTION}

The rate at which we hear and read about suicide attempts and suicide is alarming, hardly a month goes by without reports of suicide around the world. Suicide is the term used to define the act of deliberately taking one's life. Wanyoike (2015) defines suicide as an intentional, selfinflicted death which one makes an intentional direct and conscious effort to end one's life. It is a global menace that has no class distinction since it affects the very rich, the rich and the poor also it is not limited to any particular career because a teacher, lawyer, doctor, pharmacist or others in various careers can commit suicide. Suicide is common to both genders and is not limited to the aged or elderly. In fact, the rate at which adolescents commit suicide is of serious concern to parents, educationists, religious leaders, community leaders, the Government and indeed the entire populace. Researches on suicidality in the developing world are not much due to religious diversity and beliefs, socio-cultural taboos and political and economic instability. The act of committing suicide is seen as disgraceful so it is very rare for the families of the victim to openly acknowledge that their family member has committed suicide (Norhayati \& Suen, 2014).

In Nigeria, information on suicidal behaviours, suicide psychological issues and mental health problems are very limited due to some factors. One of which is that attempting or committing suicide is seen as a taboo and is discussed in quiet tones also families whose relatives commit suicide are looked down on or stigmatized. Omigbodun et al. in Adetoun and Isaac (2016) states that Nigerian students have one of the highest rates of suicidal ideation and attempts compared to other developing countries and higher than developed countries. Chukwuma (2019) stated that the rates of suicide attempts among adolescents have been put at 12 percent, it also gave examples of a 17-year-old who died after drinking insecticide (sniper) because after becoming pregnant, her grandma insisted she packed out of the house and another 19-year-old who also died using insecticide at her boyfriend's house. The World Health Organization data shows Nigeria had an age standardized suicide rate of 17.3 per 100,000 people in 2016 while the Global Health observatory puts the global age of standardized suicide rate at 11.4 per 100,000 people.

According to Amitai and Apter (2012), Suicide behaviour is a set of behaviours that includes suicidal ideation, suicidal threats, gestures, self-cutting, low lethal suicide attempts, interrupted suicide attempts, near-fatal suicide attempts and actual suicide. From this definition it is seen that suicide behaviour is a broad word used to cover a spectrum of behaviours related to suicide. These behaviours begin with suicide ideation which has to do with thoughts of killing oneself, and talking about killing oneself. Suicidal threats involve telling loved ones and significant others that someday one will take his life or in every misunderstanding, making threats of killing oneself. Self-cutting on the other hand is when an individual deliberately injures himself or herself from time to time, while the intention of not dying yet is there it is termed self-harm. The act of trying to take one's life without fatal effect is seen as low lethal suicide attempt while attempted suicide is when the suicide behaviour nearly claimed the life of the individual and finally the actual suicide. 
Print ISSN: 2054-6351(Print)

From these, it can be seen that suicide behaviour is indeed a worldwide phenomenon and a pandemic that needs to be curbed or reduced. Suicide behaviour can affect anybody irrespective of their social-economic background, race, nationality and religion.

The World Health Organisation (2022) sees adolescence as a phase of life between childhood and adulthood from the ages of 10-19. It is worthy to note that at this stage adolescents experience rapid physical, cognitive and psychological growth. However, there are factors that may lead to suicide behaviour among adolescents one of these may be Substance abuse.

It is a known fact that humans right from earliest times have made use of substances to either get relief from sickness or escape from pain. These substances may be traditionally prepared or modern from pharmaceutical companies but the abuse of substance is a major problem that is facing humanity over the years. Alloy et al, (2005) defined substance abuse as essentially a pattern of maladaptive drug use that has not progressed to full-blown dependence. They went further to explain that for an individual to be a substance abuser, he must fail to fulfill major role obligation like being absent from school, continuous use of drugs in dangerous situations like drunk driving, having legal problems because of misbehaving and the continuous use of drugs despite the social or interpersonal problems it causes. It can also be seen as the over use of drugs that are prescribed, use of illicit drugs or abuse of over-the-counter drugs. It involves the deliberate use of chemical substances for reasons other than medical purposes like for personal gratification which results in emotional, physical, mental and social impairment (Adegun et al, 2019). In addition, Myers (2009) opined that people who have trouble completing school work, maintaining healthy relationships, holding a job and interference with daily life because of conflicts over getting or using a particular substance has substance related disorders. From these definitions, it can be deduced that drugs that are prescribed by a doctor, bought in a chemist or misused in any way to the extent that it utters the individual's emotional, mental, physical and psychological well-being is substance abuse. In view of the menace that substance abuse has constituted, many countries sign multi-lateral and bilateral treaties to fight against the trafficking of drugs from one country to another. The trafficking of drugs from one country to another shows that substance abuse is on the increase and cuts across economic, social, political and racial backgrounds. In Nigeria, the National drug and law enforcement agency (NDLEA) (2012) reported that marijuana which is also known as Indian hemp is the most commonly abused substance. According to them, 16,000kg of Indian hemp and $15.6 \mathrm{~kg}$ of cocaine were seized in 1999 while $272,000 \mathrm{~kg}$ of Indian hemp and $54 \mathrm{~kg}$ of cocaine were seized in 2000 and as at 2012, Nigeria became the fourth largest country after the United States, Mexico and Bolivia in terms of marijuana seizure.

Animasahun and Animasahun (2016) examined psychosocial predictors of suicide mission among Nigerian youths. 300 students participated in the study with a total of 108 (36\%) males and $192(64.0 \%)$ females. The study adopted a descriptive survey design of the expost factor type. The ages of the participants ranges from 12-20 years with a mean of 16.11 years. Seven standardized instruments were used for the study. The findings indicated a significant joint and 
Print ISSN: 2054-6351(Print)

relative contributions of the independent variable like depression, substance abuse, self-esteem, etc. to predict suicide behaviour.

Esang and Ahmed (2018) took a closer look at substance use and suicide. This was done in order to see the association between substance abuse and suicide behaviour. It was discovered that substance use independently increases the risk of suicidal behaviour due to the fact that chronic drug abuse may impair judgement, weaken impulse, control and interrupt neurotransmitter pathway which in turn leads to suicide tendencies through disinhibition. Also, drinking of alcohol at an early age, binge or heavy drinking can lead to mild, moderate, or severe alcohol use disorder which can lead to increase in suicidal ideation. Also, persons who use alcohol heavily are five times more likely to die by suicide then social drinkers.

Haskuka et al (2017) studied the relationship between substance use and suicidal behaviour among adolescents in selected European countries in order to test the application of normalization thesis by examining levels of substance use (smoking, alcohol and cannabis) and its relation to reported suicide ideation and attempt in 13 European countries. The population was data collected from a sample of 15- year old adolescents using European school survey project on Alcohol and other drugs (ESPAD) standardized sampling strategy and data collection methodology across countries. The data was also from ESPAD study from 13 countries was used for the analysis. Findings showed that countries with low prevalence of substance use reported higher association between substance use and suicidal behaviour compared to countries with higher prevalence of substance use.

Sexual abuse is when a person engages in forced sexual activity without the consent of the individual. It is also seen as unwanted sexual activity, in which perpetrators use force, making threats or taking advantage of victims not able to give consent (American Psychological Association (APA, 2020). This definition by APA shows that victims of sexual abuse are taken advantage of, forced and do not want to engage in the sexual activity with the perpetrators. The Government of western Australia North Metropolitan Health Service King Edward Memorial Hospital (KEMH, 2021) states that child sexual abuse occurs when one under the age of 18 years has been exposed to or subjected to sexual behaviours that are exploitative, Inappropriate for the child's age and developmental level. KEMH went further to state that sexual abuse includes using the internet for grooming, exposure to sexual acts or pornographic materials, soliciting school children for sexual exploitation, inappropriate touching and sexual penetration. In the same vein Health Direct (HD, 2019) which is a government funded service that provides quality approved health information and advice opined that sexual abuse occurs when one is forced, pressured or tricked into doing sexual things when the individual does not want to. From these, it can be seen that sexual abuse is not limited to sexual penetration but it includes any sexual behaviour that makes an individual feel frightened, threatened or uncomfortable. It is worthy to note that sexual abuse can be through rape, indecent assault, incest, and sexual molestation. Perpetrators of sexual abuse could be any member of the community, teachers, family members, sports coaches, neighbours and even strangers. The long term effects of sexual abuse include anxiety, fear, post-traumatic stress disorder etc. 
Print ISSN: 2054-6351(Print)

Tae and Chae (2021). Investigated factors related to suicide attempts and the roles of childhood abuse and spirituality. This was done in other to identify independent factors associated with suicide attempts in patients with depression and /or anxiety. Patients from 18 to 65 years old from an outpatient clinic at Seoul St, Mary's Hospital were invited to join clinical studies from September 2010 to November 2017 and a total of 737 participants were included in the final sample. The Beck's Depression Inventory (BDI), State Trait Anxiety Inventory (STAI), Childhood Trauma Questionnaire (CTQ), Functional Assessment of Chronic Illness Therapyspiritual well-being scale (FACIT-SP-12) and Functional Social Support Questionnaire (FSSQ) were used to assess psychiatric symptoms while independent samples t-test, a Chisquare test, hierarchical multiple regression analyses and the Baron and Kenny's procedures were performed to analyze data. The findings showed that young age, childhood history of emotional and sexual abuse, depression, and a low level of spirituality was a significant independent factors for increased suicide attempts. Also, depression was reported to mediate the relationship between childhood emotional and sexual abuse, spirituality and suicide attempts.

Wong (2017) carried out a research on the association between child abuse and attempted suicide in Hong Kong. The aim was to identify the association between child abuse and suicide attempts in comparison with influenza infection using electronic hospital admission age $=18$ years. Data was also retrieved on suicide attempt from the hospital admission database after the first hospital admission. The population for the study were 18 years old or younger who are classified as children in Hong Kong and were patients admitted to a public hospital during the years 1995-2016 with an influenza diagnosis or child abuse. The study was quantitative in nature with non-experimental design, deductive logic and statistical analysis were used to test and interpret the hypothesis. Chi-square test, unpaired t-test and cox regression were used for research questions. The finding showed that there was a significant association between exposure to child abuse and suicide attempts when compared to the non-abused influenza group. The adjusted HR of 4.49 ( $\mathrm{P}<0.001$ ) cox regression analysis indicated that children exposed to child abuse had a 4.79 times higher chance of attempting suicide at any given time compared to children infected by influenza.

Martin et al, (2016) carried out a study on child abuse and prevalence of suicide attempts among those reporting suicide ideation. The aim was to test the association between child abuse and past year suicide attempts among those who reported suicide ideation in the past year. The population was drawn from a secondary analysis of data from a population-based Canadian Community Health Survey Mental Health $(n=828)$. The instruments used were structured questionnaires, and the composite international diagnostic interview to assess mental illness and suicidal thoughts and behaviours. Child abuse suicide thoughts and attempts, demographic, health and social variables were all measured. Dichotomous outcome using poisson regression with a robust variance estimator was used for analysis. The findings showed that participants who reported suicide ideation in the past 12 months reported high rates of child abuse $(61.2 \%)$ as well as a range of poor health and social outcomes also $14.3 \%$ of the participants who reported suicide ideation in the past 12 months attempted suicide during this same time period. 
Print ISSN: 2054-6351(Print)

In addition, the prevalence of suicide attempts was 2.56 times $(95 \% \mathrm{C} 11.29,5.08)$ higher among those reporting child abuse $(18.7 \%)$ than among those reporting child abuse $(7.3 \%)$. Lastly, the majority $(80.1 \%)$ of those with a suicide attempt reported child abuse.

Sadly, there is an apparent lack of research reports on the social variables as determinants of suicide behaviour among in-school adolescents in Rivers State, Nigeria. This gap in knowledge has spurred the researchers to action. Therefore, the problem of the study posed as a research question is "to what extent do social determinants independently and jointly relate to suicide behaviour among in-school adolescents in Rivers State, Nigeria.

\section{The objectives of the study are:}

1 Ascertain the extent substance abuse relates to suicide behaviour among in-school adolescents in Rivers State.

2 Investigate the extent sexual abuse relates to suicide behaviour among in-school adolescents in Rivers State.

3 Establish the extent social variables jointly relate to suicide behaviour among in-school adolescents in Rivers State.

The study is guided by the following research questions:

1 To what extent does substance abuse relate to suicide behaviour among in-school adolescents in Rivers State?

2 To what extent does sexual abuse relate to suicide behaviour among in-school adolescents in Rivers State?

3 To what extent does social variables jointly relate to suicide behaviour among in-school adolescents in Rivers State.

Three null hypotheses are formulated to guide the study. They are:

1 There is no significant relationship between substances abuse and suicide behaviour among in-school adolescents in Rivers State.

2 There is no significant relationship between sexual abuse and suicide behaviour among in-school adolescents in Rivers State.

3 There is no significant relationship between the joint social variables and suicide behaviour among in-school adolescents in Rivers State.

\section{METHODOLOGY}

This study was carried out in the three Federal Government Colleges in Rivers State, Nigeria. The design of the study is correlational research design. Paul et al (2017) stated that "correlational research is a type of non-experimental research in which the researcher measures 
Print ISSN: 2054-6351(Print)

two variables and assesses the statistical relationship between them, little or no effort is made to control extraneous variables in connection with correlational research.

The population of the study consist of 785 in-school adolescents in the three federal Government colleges in Rivers State who exhibit suicide behaviours. They were drawn through purposive sampling technique to form the study sample.

To identify those with suicide behaviour, the researchers administered the suicide behaviour questionnaire to all the students in the three Federal Government Colleges in Rivers State. The questionnaire contains 10 items designed to identify those that engage in suicide behaviour. The maximum score of the instrument is 20 . In determining those with suicide behaviour, the total score was divided into two, so any student who scored 20 and above was considered to elicit suicide behaviour and any that scored less than 20 was considered not to elicit suicide behaviour. In FGGC Aboluoma 257 exhibited suicide behaviour, FGC Rumuokoro 242 and FGC Ahoada 286 totaling 785 which served as the sample size of the study.

Two instruments were used for the study. The first is a standardized instrument the Suicide Behaviours Questionnaire-Revised (SBQ-R) by Osman et al. It is a self-report questionnaire designed to identify risk factors for suicide in adolescents. It is a four item questionnaire with four constructs within suicidal behaviour domain which are lifetime ideation and attempt, recent frequency of ideation, suicide threats and self-assessed likelihood of future suicidal behaviour. The researchers adapted the instrument and modified it to become 10 items It is rated on 4-point Likert type scale. The second instrument is named Determinants of Suicide Behaviour Questionnaire (DSBQ) which is a 4-point Likert type scale that contains two sections (A \& B). Section A contains demographic information and instructions on how to respond to the instrument while section $B$ contains 2 sub sections that contains items designed to elicit responses from the respondents on substance abuse and sexual abuse. The items on substance abuse and sexual abuse were developed by the researchers. The 4-point Likert type scale Strongly Agree, Agree, Disagree and Strongly Disagree (SA, A, D, SD) carries weight of 4,3,2 and 1 for positively keyed items and a reverse for negatively keyed items respectively.

The reliabilities of both SBQ-R and DSBQ were determined using Cronbach alpha via SPSS. A reliability index of 0.85 was realized for SBQ-R while for DSBQ 0.81 was realized for substance abuse and 0.68 for sexual abuse.

The researchers administered the instruments directly to the respondents with the help of 4 research assistants. Before going to the field, the researchers educated the research assistants on the purpose of the study and how to administer the questionnaires. The researchers and research assistants administered the questionnaires to only adolescents in their classes and the filled instruments were collected immediately.

Simple regression analysis was used to analyzed the data generated. Specifically, research questions 1 and 2 were analyzed using simple regression while the corresponding hypotheses were analyzed using analysis of variance associated with the regression coefficient while multiple regression was used to answer research questions 3 and it corresponding hypothesis. 


\section{RESULTS}

The results of the statistical analysis of data are presented in the following tables:

Research Question One: To what extent does substances abuse relate to suicide behaviour among in-school adolescents in Rivers State?

Table 1.1a Simple regression analysis showing $\mathrm{R}$ Correlations and $\mathrm{F}$ values for relationship between substance abuse and suicide behaviour among in-school adolescents in Rivers State.

\begin{tabular}{|lcccc|}
\hline Model & $\mathrm{R}$ & $\mathrm{R}$ Square & Adjusted R Square & Std. Error of the Estimate \\
\hline 1 & $.139 \mathrm{a}$ & .019 & .018 & 4.549 \\
\hline
\end{tabular}

The analysis in table 1.1a shows that the relationship between substance abuse and suicide behaviour is $0.139, \mathrm{R} 2$ value is 0.019 , the adjusted $\mathrm{R} 2$ value is 0.018 while the standard error of estimates is 4.549. From the R2 value, there is an indication that substance abuse has a relationship of about $1.9 \%(0.019 \times 100)$ with suicide behaviour expressed by adolescents in Rivers state.

Hypothesis One: There is no significant relationship between substance abuse and suicide behaviour among in-school adolescents in Rivers State.

Table 1.1b Showing F and Sig values of ANOVA Summary

\begin{tabular}{|c|c|c|c|c|c|c|c|}
\hline \multicolumn{2}{|l|}{ Model } & \multirow{2}{*}{$\begin{array}{l}\begin{array}{l}\text { Sum } \\
\text { Squares }\end{array} \\
317.636\end{array}$} & \multirow{2}{*}{$\begin{array}{c}\text { ofDf } \\
1\end{array}$} & \multicolumn{2}{|c|}{ Mean SquareF } & \multirow{2}{*}{$\begin{array}{l}\text { Sig } \\
0.000\end{array}$} & \multirow{2}{*}{$\begin{array}{l}\text { Result. } \\
\text {.Significant } \\
\text { (Reject Ho) }\end{array}$} \\
\hline \multirow{3}{*}{1} & Regression & & & 317.636 & 15.349 & & \\
\hline & Residual & 16224.401 & 784 & 20.694 & & & \\
\hline & Total & 16542.037 & 785 & & & & \\
\hline
\end{tabular}

The calculated F value in table $1.1 \mathrm{~b}$ is 15.349 while the Sig value is 0.000 . Since the $\operatorname{Sig}(p=0.000<0.05)$ is less than the alpha of 0.05 at 784 degrees of freedom, the null hypothesis is rejected and the alternate accepted meaning that there is a significant relationship between substance abuse and suicide behaviour among in-school adolescents in Rivers State.

Research Question Two: To what extent does sexual abuse relate to suicide behaviour among in-school adolescents in Rivers State?

Table 2.2a Simple regression analysis showing $\mathrm{R}$ Correlations and $\mathrm{F}$ values for relationship between sexual abuse and suicide behavior among in-school adolescents in Rivers State. 
British Journal of Education

Vol.10, Issue 2, pp. 1-12, 2022

Online ISSN: 2054-636X (Online)

Print ISSN: 2054-6351(Print)

\begin{tabular}{lllll}
\hline Model & R & R Square & Adjusted R Square & Std. Error of the Estimate
\end{tabular}

$\begin{array}{lllll}1 & .149 \mathrm{a} & .022 & .021 & 4.542\end{array}$

The analysis in table 2.2a shows that the relationship between sexual abuse and suicide behaviour is $0.149, \mathrm{R} 2$ value is 0.022 , the adjusted $\mathrm{R} 2$ value is .021 while the standard error of estimates is 4.542 . From the $\mathrm{R} 2$ value, there is an indication that sexual abuse has a relationship of about $2.2 \%(0.022 \times 100)$ with suicide behaviour expressed by adolescents in Rivers state.

Hypothesis Two: There is no significant relationship between sexual abuse and suicide behaviour among in-school adolescents in Rivers State.

Table 2.2b Showing F and Sig values of ANOVA Summary

\begin{tabular}{llllllll} 
Model & & Sum & ofDf & \multicolumn{2}{c}{ Mean SquareF } & Sig & Result. \\
& & Squares & & & & & \\
\hline & Regression & 366.833 & 1 & 366.833 & 17.780 & 0.000 & .Result \\
1 & Residual & 16175.204 & 784 & 20.632 & & & \\
& Total & 16542.037 & 785 & & & & \\
\hline
\end{tabular}

The calculated F value in table $2.2 \mathrm{~b}$ also is 17.78 while the Sig value is 0.000 . Since the $\operatorname{Sig}(p=0.000<0.05)$ is less than the alpha of 0.05 at 784 degrees of freedom, the null hypothesis is rejected and the alternate accepted meaning that there is a significant relationship between sexual abuse and suicide behaviour among in-school adolescents in Rivers State.

Research Question Three: To what extent does Social variables jointly relate to suicide behaviour among in-school adolescents in Rivers State.

Table 3.3 Multiple regression analysis showing $\mathrm{R}$ Correlations and $\mathrm{F}$ values for relationship between joint Social Variables and suicide behaviour among in-school adolescents in Rivers State.

\begin{tabular}{|ccccc|}
\hline Model & $\mathrm{R}$ & R Square & Adjusted R Square & Std. Error of the Estimate \\
\hline 1 & $.175 \mathrm{a}$ & .031 & .028 & 4.526 \\
\hline
\end{tabular}

The analysis in table 3.3a shows that the joint relationship between social variables and suicide behaviour is $0.175, \mathrm{R} 2$ value is 0.031 , the adjusted $\mathrm{R} 2$ value is 0.028 while the standard error of estimates is 4.526 . From the $\mathrm{R} 2$ value, there is an indication that the joint social variables account for about $3.1 \%(0.031 \times 100)$ of suicide behaviour expressed by adolescents in Rivers state.

Hypothesis Three: There is no significant relationship between the joint Social variables and suicide behaviour among in-school adolescents in Rivers State.

Table 3.3b: Showing F and Sig values of ANOVA Summary 
Print ISSN: 2054-6351(Print)

\begin{tabular}{llllllll}
\hline Model & & $\begin{array}{l}\text { Sum } \\
\text { Squares }\end{array}$ & ofDf & \multicolumn{2}{c}{ Mean SquareF } & Sig & Result. \\
\hline \multirow{4}{*}{1} & Regression & 505.58 & 3 & 252.79 & 12.34 & 0.000 & $\begin{array}{l}\text { Significant } \\
\text { (Reject Ho) }\end{array}$ \\
& $\begin{array}{l}\text { Residual } \\
\text { Total }\end{array}$ & 16036.45 & 783 & 20.48 & & & \\
\hline
\end{tabular}

The calculated F value in table $3.3 \mathrm{~b}$ also is 12.34 while the Sig Value is 0.000 . Since the $\operatorname{Sig}(\mathrm{p}=0.000<0.05)$ is less than the alpha of 0.05 at 783 degrees of freedom, the null hypothesis is rejected and the alternate accepted meaning that there is a significant relationship between the joint social variables and suicide behaviour among in-school adolescents in Rivers State, Nigeria

\section{DISCUSSION}

From research findings one, it is seen that substance abuse has a significant relationship with suicide behaviour among adolescents in Rivers State. The finding means that when adolescents abuse drugs they tend to get involved more on suicide behaviours than those who do not abuse different substances. This also implies that substance taking has a negative effect that triggers anti-social and suicide behaviours among adolescents. The researchers over the years have observed that a lot of adolescents engage in drugs even when such drugs have been proven to be deadly. Recently there is a campaign by the NDLEA on the prevalence of methamphetamine a drug called "Mkpuru Mmiri" in Igbo language. This drug has been proven to have a deadly effect on adolescents yet adolescents are still taking it. The findings may have come because a lot of adolescents agreed that substance abuse has negative effects. This finding is in line with the study of Esang and Ahmed (2018), Animasahun and Animasahun (2016) and Haskuka et al (2011) who found that substance abuse increases the risk of suicide behaviours among individuals.

From research finding two, it is revealed that sexual abuse has a significant relationship with suicide behaviour among adolescents in Rivers State. Sexual abuse has to do with wrong sexual advances that people make towards either male or female children / adolescents. The finding here means that when children or adolescents are abused sexually especially the female child, it may lead to suicide ideation or suicide behaviour in them. It also means that in a bid to overcome the trauma of sexual abuse, adolescents engage in behaviours that are dangerous and suicidal like suicide ideation, self-harm and suicide-attempt. The result of the findings may come due to the fact that adolescents especially those who have been sexually abused have lost their pride, their sense of focus as well as their dignity and as such, they think that they have nothing left in life and as a result of this they get involved in suicide related behaviours. The finding of the study is expecting and not also surprising because sexually abused children can contemplate suicide or engage in suicide related behaviours. From personal interactions and observations of the researchers, adolescents somehow tend to either engage in suicide 
Print ISSN: 2054-6351(Print)

behaviour after being raped or engage in drugs after being abused sexually. They may also be involved in prostitution having killed all forms of affection for the opposite sex. The implication of this is that, sexuality education is very important and it should start at a very early age both at home and in the school. The finding is in line with that of Tae and Chae (2021), Wong (2017) and Martin et al (2016).

From research finding three, it is also revealed that social variables jointly taken have significant relationship with suicide behaviour just as in the case explained in the findings of research question one and two. Each of these social variables had a significant contribution to suicide behaviour and a combination of them all is not expected by the researchersss to produce a different result. Hence, adolescents who are involved in substance abuse and sexual abuse have the tendency of engaging in suicide behaviours. The findings of this study are supported by other researchers as cited in the individual variables and their relationship with suicide behaviour.

\section{CONCLUSION}

Based on the findings from this study, it was concluded that social variables had significant relationship with suicide behaviour among in-school adolescents in Rivers State.

\section{Recommendations}

1. Substances that are easily abused by adolescents should be kept out of their reach and Government parastatals like Nigerian Drug and Law Enforcement Agency (NDLEA) and CUSTOM officials that are in charge of ensuring that these dangerous substances do not see the light of the day should intensify their efforts in seizing and destroying them.

2. Those that are traffickers of these substances should be counselled with therapies like CBT to help them stop trafficking dangerous substances.

3. Perpetrators of sexual abuse should be re-orientated, counselled and rehabilitated.

\section{REFERENCES}

Adegun, A.O., \& Jiboku, A. (2019). Drug use and mental health among adolescents in Nigeria. Emerging issues and counseling implication. Journal of Professional Counseling (JPC), 2(1), 10-28.

Adetoun, O. O, \& Isaac, T. O. (2016). Depression and suicidal ideation among college students with and without learning disabilities in Nigeria. The European Journal of social and Behavioural Sciences, 16(2), 2218-2301. http://dx.doi.org/ 10.15405/ejsbs

Alloy, L.B. Riskino, J. H., Manos, M.J. (2005) .Abnormal psychology current perspectives (9thed.). McGraw-Hill.

Amitai, M. \& Apter, A. (2012). Social aspects of suicidal behavior and prevention in early life: A review on International Journal of Environmental Research and public Health, 
Print ISSN: 2054-6351(Print)

9 (3), 985-994.American Psychological Association (2020).Sexual abuse?www.kemh.health.wa.gov.au>SARC

Animasahun, R.A., \& Animasahun, V.O. (2016). Psychosocial predictors of suicide mission among Nigerian youths. African Journal for the Psychological Studies of Social Issues 19(1), 67-70.

Chukwuma, M., Stanley, A. \& Adaku.O. (2019). Addressing rising cases of suicide among teenage in Nigeria. Guardian. Ng 21th May 2019.

Esang, M., \& Ahmed, S. (2018). A closer look at substance use and suicide. The American Journal of Psychiatryhttps://doi.org/10.1176/appi.ajp-rj.2018.130603

Haskuka, M., Arenliu, A., Kelmendi, K. (2017). Helping children and young people who self - harm an introduction to self - harming and suicidal behaviours for health professional Routledge.

Health Direct (2019). Sexual abuse / www.healthdirect.gov.au>sexual -a......

Martins M.S., Dykxhoorn, J., Afifi, T.O., \& Colman, I. (2016). Child abuse and the prevalence of suicide attempts among those reporting suicide ideation. Social psychiatry Epidemiology.51(11), 1477-1484 www.ncbi.nlm.nih.gov doi: 10.1007/s00127-0161250-3

Myers, D. G. (2009). Psychology in everyday life. Worth publishers

NDLEA (2012). National Drug and law enforcement Agency statistical report

Paul, C.P., Rajiv, S., I-Chant, A.C., \& Dana, C. (2017). Research methods in psychology.2nd American edition DOI 10.17605/0SF.10/2J3PT/ARKc7605/osf.10/2j3pt

Tae, H.\& Chae, J.H C., (2021). Factors related to suicide attempts: The roles of childhood abuse and spirituality. Front. Psychiatry 12:565358. doi:10.3389/fpsyt.2021.565358

Wanyoike, B.W. (2015). Suicide Among University students in Kenya: causes, Implications and Interventions. Journal of language, Technology \& Entrepreneurship in Africa Vol 6. No 1

Wong, H. S. W. (2017). The association between child abuse and attempted suicide in Hong Kong. Dissertation submitted in partial fulfillment of the requirement for the degree of Doctor of Philosophy. College of Health Science Walden University

The centre for suicide prevention (2021). Substance abuse disorder and suicide https://www. Nationalelfservice.net $>$...

The Government of western Australia North metropolitan health service king Edward memorial

Hospital (KEMH) (2021). Sexual assault resource centre https://www.kemh.health.wa.gov $. \mathrm{au}>\ldots$

Wong, H. S. W. (2017). The association between child abuse and attempted suicide in Hong Kong. Dissertation submitted in partial fulfillment of the requirement for the degree of Doctor of Philosophy. College of Health Science Walden University. The Government of western Australia North metropolitan health service king Edward memorial hospital (KEMH) (2021)

World Health Organization (2022). Adolescent health https//www.int>topics

World Health Organization (2021). Substance abuse- www.who.int> topics> substance-a... 